\title{
Thermomechanical properties of PMMA and modified SWCNT composites
}

This article was published in the following Dove Press journal:

Nanotechnology, Science and Applications

8 February 2017

Number of times this article has been viewed

\section{P Kalakonda ${ }^{1,2}$}

\section{S Banne ${ }^{3}$}

'Department of Physics,

Worcester Polytechnic Institute,

Worcester, MA, USA; ${ }^{2}$ Department

of Materials Science and Engineering,

Carnegie Mellon University,

Pittsburgh, PA, USA; ${ }^{3}$ School of

Pharmaceutical Sciences and Innovative Drug Research Centre,

Chongqing University, Chongqing,

People's Republic of China
Correspondence: P Kalakonda Department of Materials Science and Engineering, Carnegie Mellon University, Pittsburgh, 5000 Forbes Ave, PA 15205, USA

Email parvathalu.k@gmail.com
Abstract: It is well known that the addition of carbon nanotubes (CNTs) can strongly affect the thermomechanical and electrical properties of the polymer into which they are dispersed. The common solvent mixing dispersion method of functionalized CNTs and polymer composites can improve thermal, mechanical, and electrical properties. In this study, functionalized single-walled CNTs (COOH-SWCNTs) and poly(methyl methacrylate) were used to fabricate the polymer nanocomposites using a common solvent dispersion mixing method. The homogenous dispersion of COOH-SWCNTs in the composites resulted in improved thermomechanical properties of these composites; this was analyzed using scanning electron microscopy.

Keywords: polymer nanocomposites, thermal-mechanical properties, functionalization, common solvent mixing

\section{Introduction}

In the last two decades, the polymer nanocomposites have drawn desirable interest in industry and research. ${ }^{1-3}$ The carbon nanotubes (CNTs) have exceptional properties of electrical, ${ }^{4-5}$ thermal, ${ }^{5}$ and mechanical, in combination with their low mass density, large aspect ratio, and higher surface area per mass which would make them an ideal reinforcing agent to impart these multifunctional properties to the polymers. ${ }^{6-8}$ Consequently, the large surface area of polymer nanocomposite materials fully exposes to specific functionalities, while the structure of the material maintains with desired mechanical properties.

The single-walled CNTs (SWCNTs) added higher thermal stability, ${ }^{7}$ electrical conductivity $^{6,8}$ to the polymer nanocomposites. The SWCNTs also induced substantial mechanical enhancements of composites. ${ }^{9-11}$ Among many polymers, poly(methyl methacrylate) (PMMA) ${ }^{12-13}$ has attracted significant attention because of easy synthesis, amorphous nature, optical clarity, biocompatibility, degradability, and has emerged as a promising material for transparent electronics, textile industry, aerospace engineering, and electromagnetic interface shielding materials. ${ }^{14-16}$ Recently, SWCNTs have been incorporated into several polymers with mixed multifunctional properties results. ${ }^{17-23}$ Two major problems needed to achieve exceptional multifunctional properties of SWCNTbased polymer nanocomposites. The first problem is a homogeneous dispersion of SWCNT in a polymer matrix and second is a stronger interfacial adhesion with a polymer to promote efficient load transfer from a polymer matrix to nanoubes. ${ }^{24-28}$ Unfortunately, SWCNT aggregates when simply mixed with a polymer due to stronger van der Waal attraction between CNTs than the interaction between polymers and CNTs. ${ }^{17-23}$ 
Many fabrication methods have been developed (solution mixing, melt-compounding, etc.) to incorporate SWCNT into matrix..$^{14-16,29-33}$ However, the dispersion of SWCNT with different solvents and polymer leads to highly aggregated SWCNT composites. The functionalization of SWCNTs reduced SWCNTs aggregation and allowed chemical crosslinking of SWCNTs to polymers, which lead to enhanced interfacial interactions with polymers. ${ }^{17,22}$ However, this approach destroyed intrinsic properties of nanotubes and mechanical reinforcements. ${ }^{17}$

In this study, we have focused on incorporating functionalized SWCNT (COOH-SWCNT) into PMMA polymer matrix. SWCNT/PMMA composites are useful for a wide range of applications from household to automobile in day-to-day life. The main focus of this study is to achieve a homogeneous dispersion of SWCNT in polymer matrix via common solvent dispersions ${ }^{34}$ and to improve multifunctional properties. The composites were fabricated with various COOH-SWCNT loadings and their thermal, mechanical, and electrical properties were measured. The composites at $5 \mathrm{wt} \% \mathrm{COOH}-\mathrm{SWCNT}$ loading enhanced mechanical and electrical properties for a wide range of industrial application.

\section{Experimental section}

\section{Materials}

COOH-SWCNTs used in this work were purchased from Cheaptubes, Inc., (Brattleboro, VT, USA) with a relative purity $>95 \mathrm{wt} \%$. The dimension of the SWCNTs was $5-10 \mathrm{~nm}$ in outer diameter, $1-5 \mathrm{~nm}$ in inner diameter, and 5-30 $\mu \mathrm{m}$ in length. The polymer matrix used in this work - PMMA - was purchased from Thermo Fisher Scientific, Waltham, MA, USA (includes Thermo Scientific and Fisher Scientifc).

\section{Preparation of $\mathrm{COOH}-\mathrm{SWCNT}$ with PMMA}

To reduce aggregation, a small amount of $\mathrm{COOH}-\mathrm{SWCNTs}$ was dispersed first in chloroform and underwent mechanical stirring for 1 hour, followed by tip sonication (in a water bath) for 2 hours. The PMMA was dispersed in chloroform and underwent mechanical stirring for 1 hour, followed by bath sonication for 2 hours. The two above dispersed solutions sharing common solvent chloroform, but containing COOH-SWCNTs and PMMA polymer, respectively. The PMMA solution was added to COOH-SWCNT solution to achieve the desired final weight percent of COOH-SWCNTs. The mixture then was bath sonicated for 2 hours to facilitate dispersion. Finally, chloroform was evaporated and then degassed under a modest vacuum. Here, we used chloroform as the common solvent that would be the optimum solvent ${ }^{35}$ to disperse COOH-SWCNTs in the PMMA polymer matrix.

\section{Characterization}

Fourier transform infrared spectroscopy (FTIR):

The chemical compositions of composite fibrous scaffold were collected by using a FTIR (FTIR-6700 Smart FTIR spectrometer ranging from 4,000 to $400 \mathrm{~cm}^{-1}$ )

\section{Electron microscopy}

The microstructure of composite scaffold was imaged using scanning electron microscopy. Nova Nano 630 was used to obtain high-resolution scanning electron microscope images.

\section{Mechanical testing}

The tensile stress $(\sigma)$ was measured as a function of tensile strain $(\epsilon)$ at a rate of $1 \mathrm{~mm} / \mathrm{s}$ at room temperature with a $5 \mathrm{~N}$ load cell using dynamic mechanical analysis system (TA Instruments). For the tensile measurements, including the testing of plastic sheets with the thickness $<0.25 \mathrm{~mm}$, the American Society for Testing and Materials (ASTM) standard ASTM D 882 was followed.

\section{Thermal analysis}

Differential scanning calorimetry (DSC) measurements were carried out with a DSC-204 F1 (Netzsch) at a heating rate of $5^{\circ} \mathrm{C} / \mathrm{min}$. Thermogravimetric analysis was carried out under atmospheric $\mathrm{N}_{2}$ over a temperature range of $25^{\circ} \mathrm{C}-800^{\circ} \mathrm{C}$ using a TG-209F (Netzsch) at a heating rate of $5^{\circ} \mathrm{C} / \mathrm{min}$.

\section{Electrical conductivity}

For electrical conductivity measurements of the composite, copper foil leads were connected or attached to the short ends of the rectangular composites with silver paste, and resistance was measured using a two-probe contact direct current method.

\section{Results and discussion}

The first main challenge is to separate the SWCNTs from their initial aggregated assemblies, which is achieved by local shear forces and functionalization. The simple manual mixing of SWCNTs with PMMA polymer matrix does not create a local shear force and, therefore, leads to nonuniform dispersion of SWCNTs inside PMMA polymer matrix. For effective separation of SWCNT bundles, physical and chemical approaches such as mechanical stirring, sonication, and surface functionalization have been employed. Briefly, the 
fabrication of composites, the dispersion of COOH-SWCNTs could be aided by the introduction of a common solvent an organic solution of chloroform ${ }^{36}$ that dissolves PMMA easily and at the same time allows uniform dispersion of COOH-SWCNTs. The two solutions are shared via common solvent chloroform containing $\mathrm{COOH}-\mathrm{SWCNT}$ s and PMMA polymer, respectively, undergo mechanical stirring for 1 hour followed by sonication process for 2 hours. Following that, the two solutions were mixed for a further 2-hour bath sonication. Finally, with the complete evaporation of the solvent, $\mathrm{COOH}-$ SWCNTs would be left well dispersed in polymer matrix. Here, chloroform was used as the common solvent that would be the optimum solvent ${ }^{36}$ to disperse $\mathrm{COOH}-\mathrm{SWCNTs}$ in the PMMA polymer matrix. The PMMA polymer may be covalently bonded to the $\mathrm{COOH}-\mathrm{SWCNT}$ s surface, and this will lead to stronger interfacial interactions. It is important to study and understand different functional groups on the composites to examine the structure of composites.

\section{FTIR}

Examples of FTIR spectra obtained for pristine PMMA, COOH-SWCNTs, and composites are shown in Figure 1. In pristine PMMA polymer, there was a sharp, intense peak that appeared at $1,730 \mathrm{~cm}^{-1}$ due to the presence of ester carbonyl group $(\mathrm{C}=\mathrm{O})$ stretching vibration. The broader peak appeared ranging from 1,300 to $1,000 \mathrm{~cm}^{-1}$ due to the presence of ester bond $(\mathrm{C}-\mathrm{O})$ stretching vibration. There was also another broad peak observed ranging from 3,500 to $2,850 \mathrm{~cm}^{-1}$ and $1,195 \mathrm{~cm}^{-1}$ due to the presence of $-\mathrm{O}-\mathrm{CH}_{3}$ group stretching vibration. The peaks at $2,951 \mathrm{~cm}^{-1}, 1,449 \mathrm{~cm}^{-1}$ appeared due to $\mathrm{C}-\mathrm{H}$ stretching and $\mathrm{CH}_{3}$ stretching vibrations in

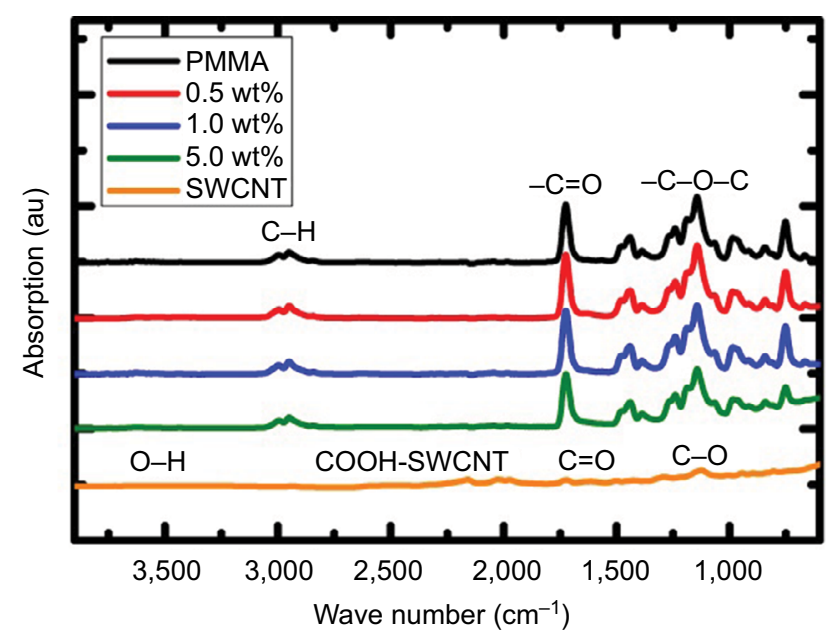

Figure I Fourier transform infrared spectroscopy spectra of the PMMA, SWCNT, and COOH-SWCNT/PMMA composites.

Abbreviations: PMMA, poly(methyl methacrylate); SWCNT, single-walled carbon nanotube; COOH-SWCNT, functionalized SWCNT.
PMMA. ${ }^{37,38}$ In COOH-SWCNTs, the peaks appeared due to $\mathrm{C}=\mathrm{C}$ conjugation typically at $1,590 \mathrm{~cm}^{-1}$ and $\mathrm{C}-\mathrm{C}$ band at $1,120 \mathrm{~cm}^{-1}$ and $3,435 \mathrm{~cm}^{-1}, 1,720 \mathrm{~cm}^{-1}$ can be attributed to the stretching vibration of $\mathrm{O}-\mathrm{H}$ and $\mathrm{C}=\mathrm{O}$ carboxyl groups. ${ }^{39}$ The peak at $1,280 \mathrm{~cm}^{-1}$ can be attributed to $\mathrm{C}-\mathrm{O}$ stretching vibration. The presence of these three peaks suggests that $\mathrm{COOH}$ groups have been introduced on the surface of SWCNTs. ${ }^{40,41}$

\section{Electron microscopy}

The fracture surface morphology of composites at two different $\mathrm{COOH}-\mathrm{SWCNT}$ s loading is shown in Figure 2. The dispersion and aspect ratio of $\mathrm{COOH}-\mathrm{SWCNTs}$, porosity play a critical role in improving thermomechanical and electrical properties. The homogeneous dispersion of modified SWCNTs is achieved at $0.5 \mathrm{wt} \% \mathrm{COOH}-\mathrm{SWCNT}$ loading (Figure 2), and highly packed homogeneous dispersion is observed at $5 \mathrm{wt} \%$ COOH-SWCNT loading (Figure 2). The scanning electron microscopy (SEM) micrographs of composites confirm the good homogeneous distribution of the COOH-SWCNTs and indicate a fine dispersion at the microscale. The homogeneous dispersion of modified SWCNTs covalently bonded to the PMMA polymer would improve thermal, mechanical, and electrical properties due to the stronger interfacial interactions between polymer and SWCNTs.

\section{Mechanical testing}

The mechanical characterization was carried out for the pristine PMMA and COOH-SWCNTs/PMMA composites. The composite samples used for all mechanical measurements were rectangular with an average thickness of 100-150 $\mu \mathrm{m}$. Figure 3A shows the stress-strain curve for pristine PMMA and $\mathrm{COOH}-\mathrm{SWCNT} / \mathrm{PMMA}$ composites, and the first $0 \%-5 \%$ strain range was considered as a linear region for tensile modulus measurements. The tensile modulus of pristine PMMA showed about $450 \mathrm{MPa}$; the COOH-SWCNT/ PMMA composites were improved tensile modulus by $\sim 300 \%$ (Figure 3B). The ultimate tensile strength of composites increased suddenly at $0.5 \mathrm{wt} \%$ and then increased slowly as the function of SWCNT loading (Figure 4A).

The ultimate tensile strength of composites at $5 \mathrm{wt} \%$ COOH-SWCNT loading was enhanced by $\sim 3(300 \%)$ times higher compared to the pristine PMMA. The tensile strain (elongation) decreased from $30 \%$ to $9 \%$ at $5 \mathrm{wt} \% \mathrm{COOH}-$ SWCNT loading (Figure 4B). The higher COOH-SWCNT loading may lead to dense packing with polymer due to the stronger interfacial interaction between modified SWCNT and polymer. The composite at $5 \mathrm{wt} \%$ showed higher modulus (E), higher ultimate tensile strength, and higher stiffness compared 

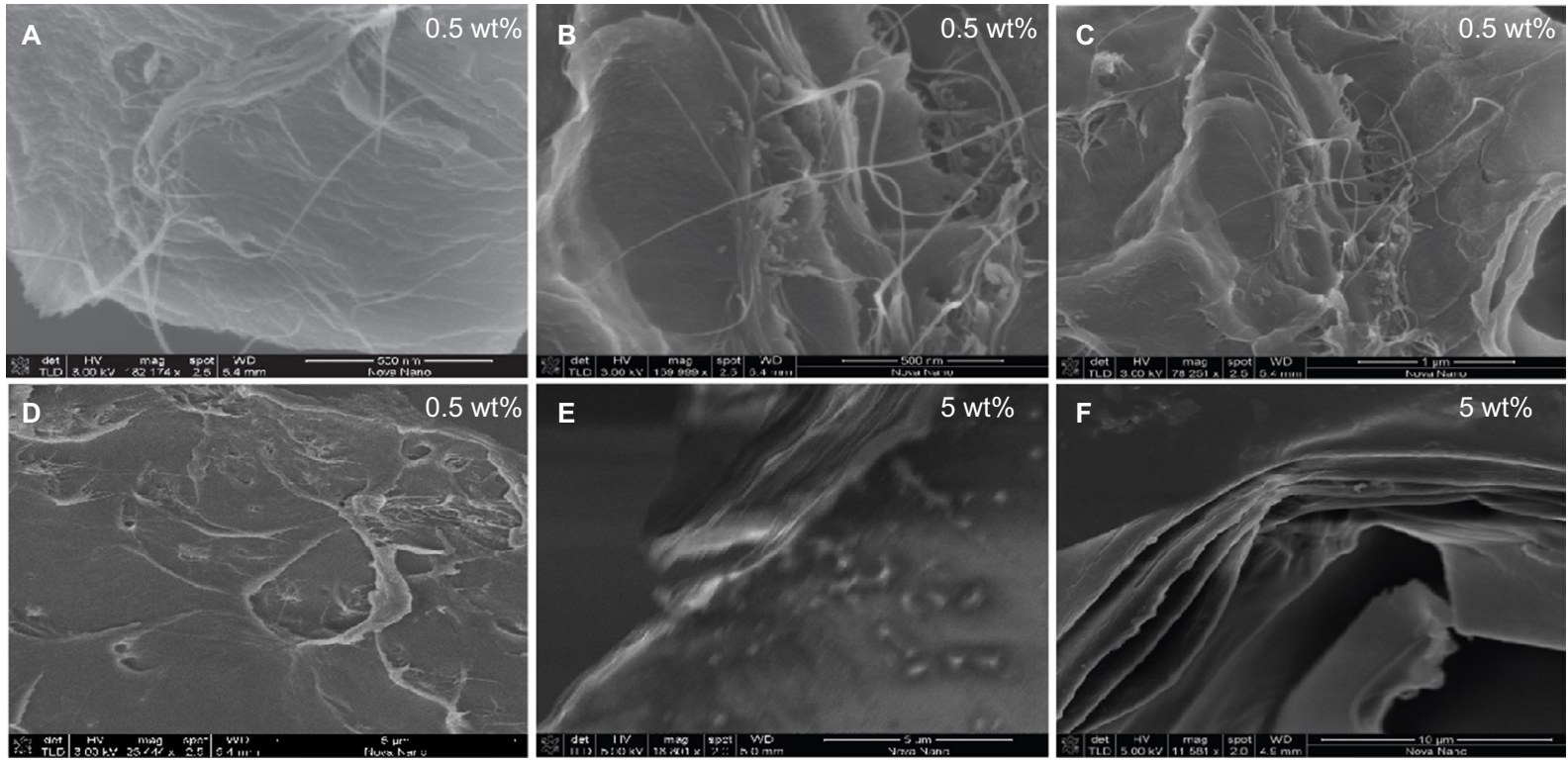

Figure 2 Scanning electron microscopy micrographs of the SWCNT/PMMA composites (A) $0.5 \mathrm{wt} \%-500 \mathrm{~nm}$, (B) $0.5 \mathrm{wt} \%-500 \mathrm{~nm},(\mathbf{C}) 0.5 \mathrm{wt} \%-\mathrm{I} \mu \mathrm{m}$, (D) $0.5 \mathrm{wt} \%-5 \mu \mathrm{m}$, (E) $5 \mathrm{wt} \%-5 \mu \mathrm{m}$, and (F) $5 \mathrm{wt} \%-10 \mu \mathrm{m}$.

Abbreviations: PMMA, poly(methyl methacrylate); SWCNT, single-walled carbon nanotubes; wt, weight.

A

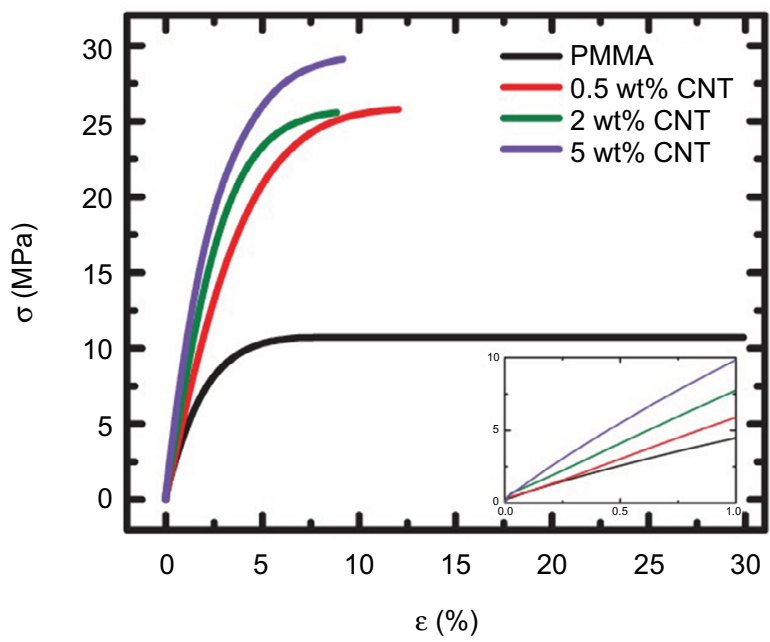

B

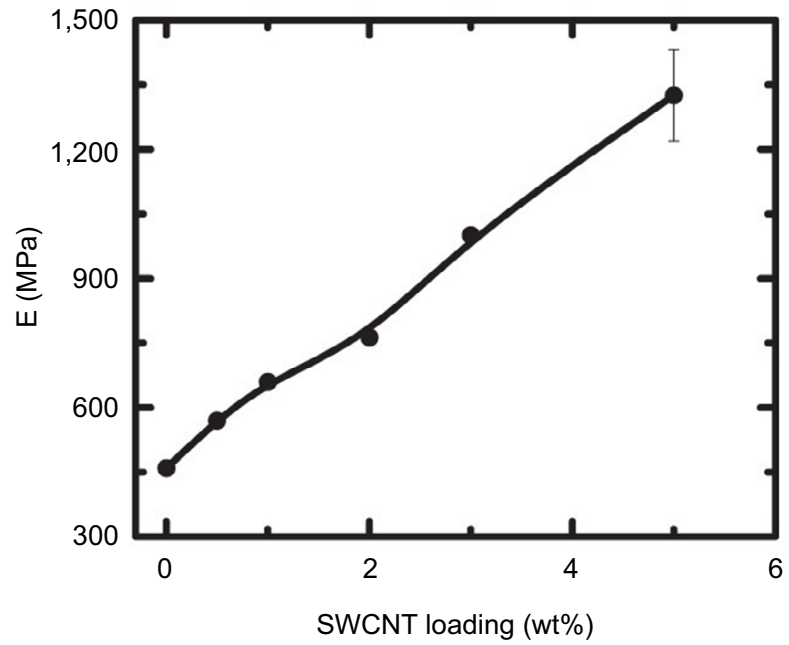

Figure 3 Mechanical characteristics of the $\mathrm{COOH}-\mathrm{SWCNT/PMMA}$ composites:

Notes: $(\mathbf{A})$ Tensile stress $(\sigma)$ versus tensile strain ( $\varepsilon$ curves); (B) tensile modulus (E) of the COOH-SWCNT/PMMA composites as the function of COOH-SWCNT loading. Insert graph shows linear region.

Abbreviations: CNT, carbon nanotube; $\mathrm{COOH}-\mathrm{SWCNT}$, functionalized single-walled carbon nanotube; PMMA, poly(methyl methacrylate); wt, weight.

to pristine polymer due to more tightly packed polymer and modified SWCNT morphology. The pristine polymer showed a higher stretching (larger strain), and the stretching behavior becomes significantly lower due to the higher brittleness at $5 \mathrm{wt} \% \mathrm{COOH}-\mathrm{SWCNT}$ loading. As a result, $5 \mathrm{wt} \% \mathrm{COOH}-$ SWCNT loading seems optimum for modified SWCNT loading for smart industrial composite material.

\section{Thermal analysis}

To explain the main origin of mechanical enhancement of these nanocomposites, we examined composite glass transition and stiffness, both of which lead to enhance modulus (E) by using DSC analysis and dynamic mechanical analysis. The DSC thermograms (considered second runs to erase any effect of thermal history) is shown in Figure 5. For the pristine PMMA, the glass transition temperature (step in heat flow and calculated $\mathrm{T}_{\mathrm{g}}$ as the midpoint of the extrapolated heat flow) appeared at $96.5^{\circ} \mathrm{C}$. The glass transition temperature of composites increases $\sim 1^{\circ} \mathrm{C}$ at $5 \mathrm{wt} \% \mathrm{COOH}-\mathrm{SWCNT}$ loading and shows that no significant change is observed.

The COOH-SWCNTs induced constrained thermal motion of polymer through the altering glass transition 


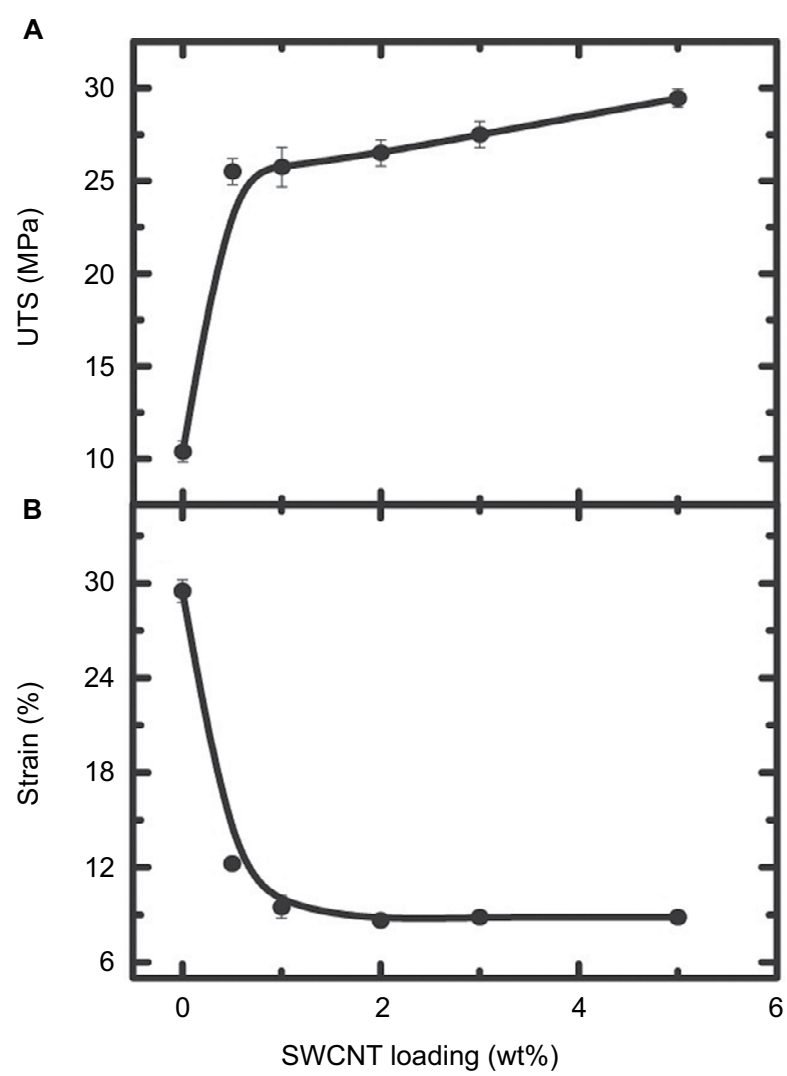

Figure 4 The mechanical characteristics of $\mathrm{COOH}-\mathrm{SWCNT/PMMA}$ composites. Notes: (A). The UTS of the COOH-SWCNT/PMMA composites with $\mathrm{COOH}$ SWCNT loading. (B) The tensile strain of the COOH-SWCNT/PMMA composites with modified $\mathrm{COOH}$-SWCNT loading.

Abbreviations: $\mathrm{COOH}-\mathrm{SWCNT}$, functionalized single-walled carbon nanotube; PMMA, poly(methyl methacrylate); UTS, ultimate strength.

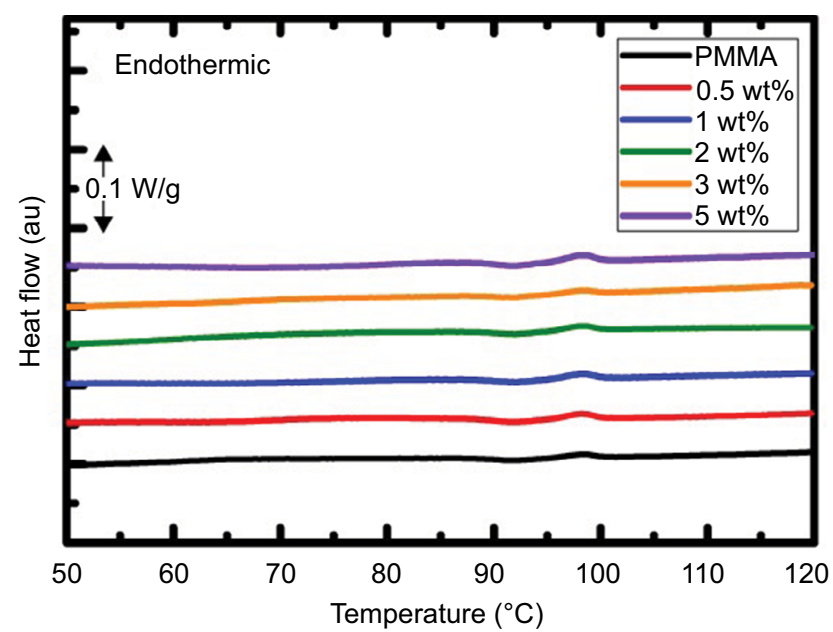

Figure 5 Differential scanning calorimetry measurements of pristine PMMA and $\mathrm{COOH}-\mathrm{SWCNT/PMMA}$ composites with the function of modified SWCNT loading. Abbreviations: $\mathrm{COOH}-\mathrm{SWCNT}$, functionalized single-walled carbon nanotube; PMMA, poly(methyl methacrylate); wt, weight.

temperature of the polymer. The viscoelastic properties (glass transition temperature [ $\tan \delta$ ], storage modulus) of COOH-SWCNT/PMMA composites were examined from the dynamic mechanical analysis measurements (Figure 6B).

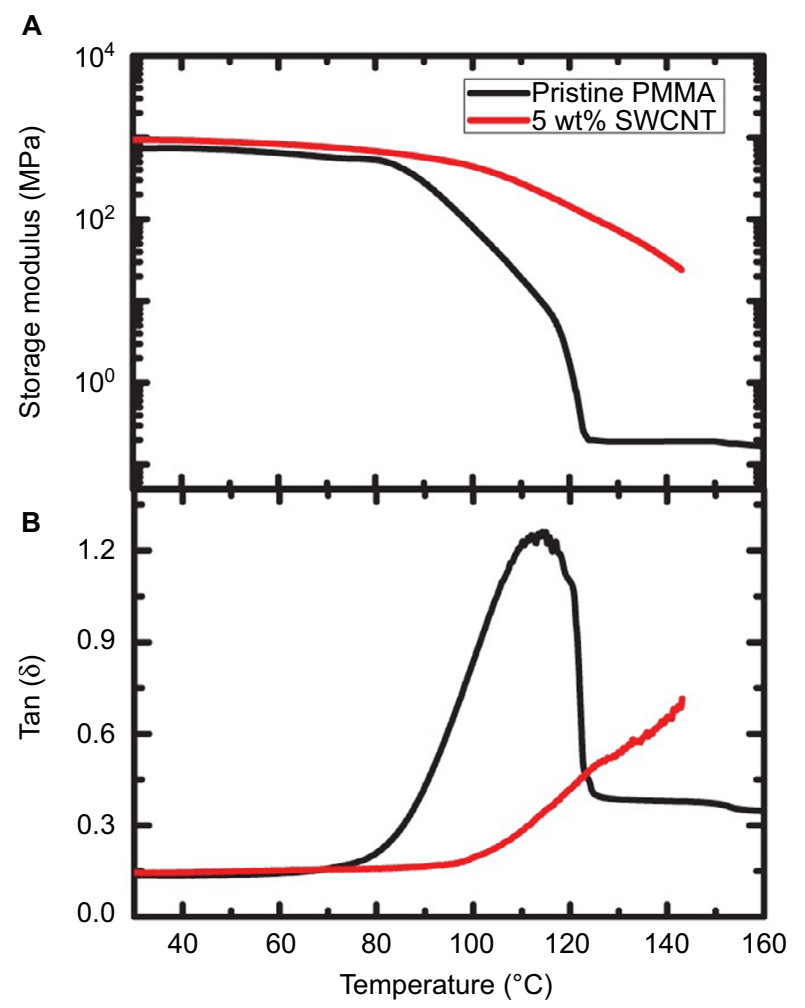

Figure 6 The glassy behavior of COOH-SWCNT/PMMA composites.

Notes: (A) The storage modulus versus temperature measurements showed that the modified SWCNT extended mechanical integrity of composites above the polymer melting temperature. (B) Damping ratio $(\tan \delta)$ versus temperature also showed an enhancement in melting transition temperature of the composites. Abbreviations: PMMA, poly(methyl methacrylate); SWCNT, single-walled carbon nanotube.

The glass transition temperature of the pristine PMMA showed at $113^{\circ} \mathrm{C}$, and the glass transition temperature shifted $10^{\circ} \mathrm{C}$ to higher temperature for COOH-SWCNT/ PMMA composite at $5 \mathrm{wt} \% \mathrm{COOH}-\mathrm{SWCNT}$ loading. Further, the storage modulus ( $\left.\mathrm{E}^{\prime}\right)$ of composite $(5 \mathrm{wt} \%)$ increased compared to the pristine PMMA (Figure 6A) at room temperature. The modulus of the pristine PMMA and COOH-SWCNT/PMMA composite (at room temperature) was closely comparable to the tensile modulus measured from the tensile test (Figure 3B).

The pristine PMMA started fracturing at lower temperature due to the softness of polymer (softer backbone), whereas the mechanical fracture of composite shifted to a higher temperature, which suggested that modified SWCNT acted as a stronger reinforcement (mechanical integrity) to the pristine polymer. The modified SWCNTs restricting the polymer motion led to increasing the stiffness of the composite material and contributed to mechanical reinforcement.

To elucidate COOH-SWCNT/PMMA composites' thermal stability, composite thermal stability was also 
examined using the thermogravimetric analysis shown in Figure 7A. The mass loss of polymer in composites associated with burning off reduced in the presence of modified SWCNTs. The rate of mass loss showed that degradation temperature of composites shifted to a higher temperature in the presence of $\mathrm{COOH}-\mathrm{SWCNTs}$ (Figure 7B). The thermal stability was improved by $50^{\circ} \mathrm{C}$ for composites at 5 $\mathrm{wt} \%$ modified SWCNT loading. The composites at $5 \mathrm{wt} \%$ COOH-SWCNT loading left $18 \%$ weight even at $800^{\circ} \mathrm{C}$, and this might be due to nanoconfinement of polymer coating on COOH-SWCNTs.

\section{Electrical conductivity}

The electrical conductivity was found to be $1 \times 10^{-10} \mathrm{~S} / \mathrm{cm}$ for pristine PMMA, and the conductivity significantly increased $34 \mathrm{~S} / \mathrm{cm}$ at $0.5 \mathrm{wt} \% \mathrm{COOH}-\mathrm{SWCNT}$ loading (Figure 8). It is believed that the percolation threshold was established at $<0.5 \mathrm{wt} \% \mathrm{COOH}-\mathrm{SWCNT}$ loading, and significantly $(1500 \%)$ higher electrical conductivity was observed. The

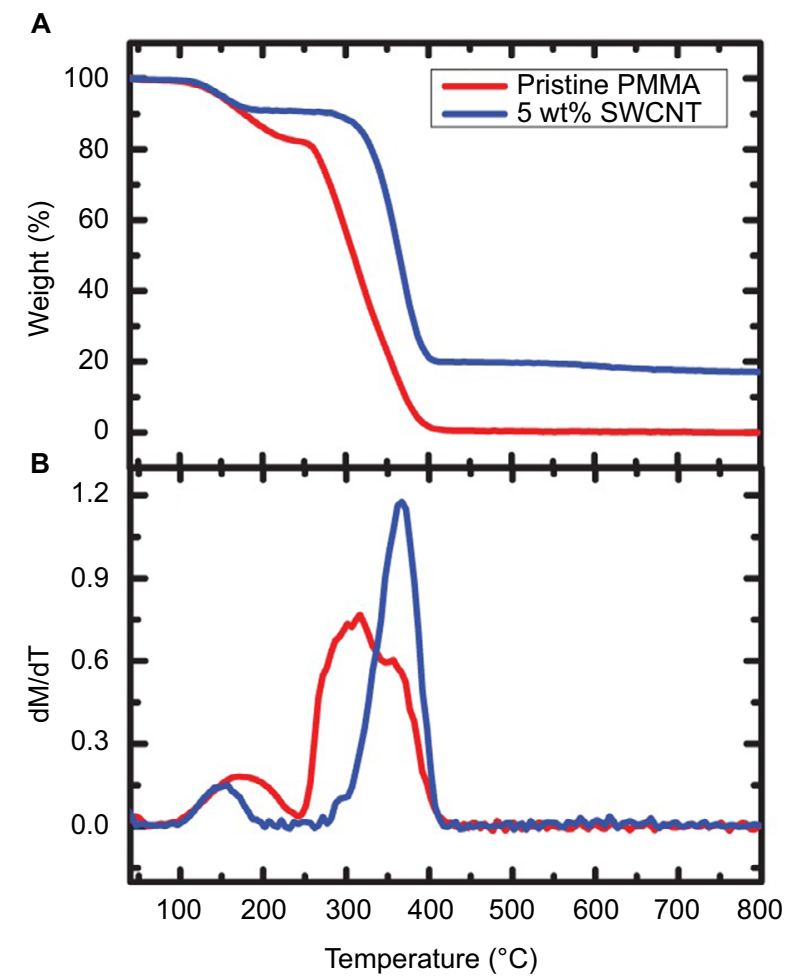

Figure 7 Thermal stability of the pristine polymer PMMA and COOH-SWCNT/ PMMA composites:

Notes: (A) Thermogravimetric analysis of PMMA, and COOH-SWCNT/PMMA composites under a nitrogen atmosphere. The mass loss in polymer associated with burning off polymer reduced in the presence of the modified SWCNTs; (B) examination of the rate of mass loss showed that decomposition of composites significantly shifted to higher temperature with the modified SWCNT loading. Abbreviations: $\mathrm{COOH}-\mathrm{SWCNT}$, functionalized single-walled carbon nanotube; PMMA, poly(methyl methacrylate); wt, weight.

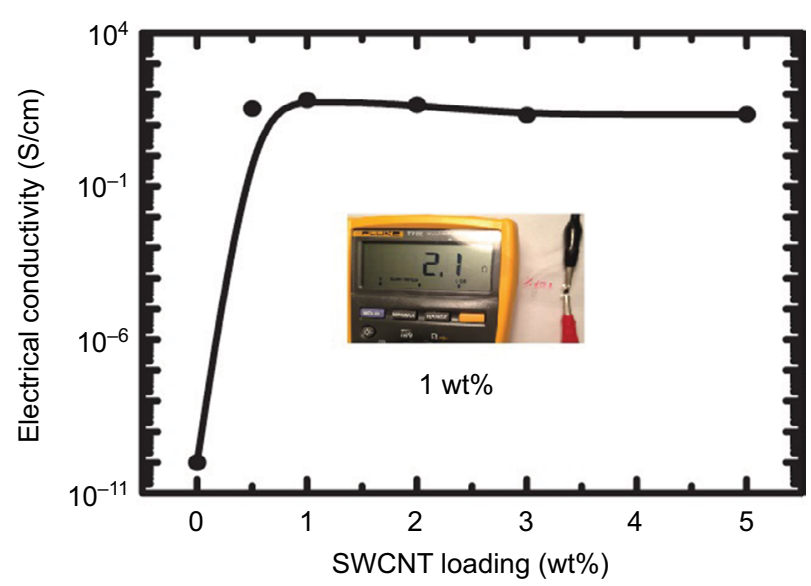

Figure 8 Electrical conductivity of COOH-SWCNT/PMMA composites with the function of modified SWCNT loading.

Abbreviations: $\mathrm{COOH}-\mathrm{SWCNT}$, functionalized single-walled carbon nanotubes; PMMA, poly(methyl methacrylate); wt, weight.

increase in conductivity was observed up to $1 \mathrm{wt} \% \mathrm{COOH}-$ SWCNT loading. The increase in conductivity may be due to the stronger interfacial interaction between SWCNT and polymer. The conductivity started to decrease above $1 \mathrm{wt} \%$ COOH-SWCNT loading, and the conductivity becomes constant $(20 \mathrm{~S} / \mathrm{cm})$ up to $5 \mathrm{wt} \% \mathrm{COOH}-\mathrm{SWCNT}$ loading. The decline in conductivity may be due to higher contact resistance between $\mathrm{CNT}$ junctions $(\mathrm{CNT}-\mathrm{CNT})$.

\section{Conclusion}

In this study, we fabricated the composites of $\mathrm{COOH}-$ SWCNT/PMMA using a common solvent dispersion method that would be useful to overcome some limitations in the smart material industry. The tensile modulus and ultimate tensile strength of these composites were improved $\sim 300 \%$ over the pristine PMMA sample. The electrical conductivity of composites significantly increased $34 \mathrm{~S} / \mathrm{cm}$ at $1 \mathrm{wt} \%$ COOH-SWCNTs loading. The modified SWCNTs reduced the thermal motion of polymer, resulting in an extension of mechanical structural integrity. The COOH-SWCNT/PMMA composites were thermally stable. The fabrication and characterization of $\mathrm{COOH}-\mathrm{SWCNT} / \mathrm{PMMA}$ composite smart materials are of great interest against optical and aerospace industrial applications.

\section{Acknowledgment}

This work was supported by the Department of Physics at Worcester Polytechnic Institute (WPI), Worcester, USA.

\section{Disclosure}

The authors report no conflicts of interest in this work. 


\section{References}

1. Breuer O, Sundararaj U. Big returns from small fibers: a review of polymer/carbon nanotube composites. Polym Composite. 2004;25(6): 630-645.

2. Moniruzzaman M, Winey KI. Polymer nanocomposites containing carbon nanotubes. Macromolecules. 2006;39(16):5194-5205.

3. Marx W, Barth A. Carbon nanotubes - a scientometric study. Phys Status Solidi B. 2008;245(10):2347-2351.

4. Islam MF, Milkie DE, Kane CL, Yodh AG, Kikkawa JM. Direct measurement of polarized absorption cross-section of single wall carbon nanotubes. Abstr Pap Am Chem S. 2004;228:U491-U491.

5. Johnston DE, Islam MF, Yodh AG, Johnson AT. Electronic devices based on purified carbon nanotubes grown by high-pressure decomposition of carbon monoxide. Nat Mater. 2005;4(8):589-592.

6. Bryning MB, Islam MF, Kikkawa JM, Yodh AG. Very low conductivity threshold in bulk isotropic single-walled carbon nanotube-epoxy composites. Adv Mater. 2005;17(9):1186-1191.

7. Kashiwagi T, Du FM, Douglas JF, Winey KI, Harris RH, Shields JR. Nanoparticle networks reduce the flammability of polymer nanocomposites. Nat Mater. 2005;4(12):928-933.

8. Gui XC, Li HB, Zhang LH, et al. A facile route to isotropic conductive nanocomposites by direct polymer infiltration of carbon nanotube sponges. ACS Nano. 2011;5(6):4276-4283.

9. Vigolo B, Penicaud A, Coulon C, et al. Macroscopic fibers and ribbons of oriented carbon nanotubes. Science. 2000;290(5495):1331-1334

10. Coleman JN, Khan U, Blau WJ, Gun'ko YK. Small but strong: a review of the mechanical properties of carbon nanotube-polymer composites Carbon. 2006;44(9):1624-1652.

11. Kobashi K, Nishino H, Yamada T, Futaba DN, Yumura M, Hata K. Epoxy composite sheets with a large interfacial area from a high surface area-supplying single-walled carbon nanotube scaffold filler. Carbon. 2011;49(15):5090-5098.

12. Kang IP, Schulz MJ, Kim JH, Shanov V, Shi DL. A carbon nanotube strain sensor for structural health monitoring. Smart Mater Struct. 2006;15(3):737-748.

13. Pham GT, Park YB, Liang Z, Zhang C, Wang B. Processing and modeling of conductive thermoplastic/carbon nanotube films for strain sensing. Compos Part B-Eng. 2008;39(1):209-216.

14. Kim HM, Kim K, Lee CY, et al. Electrical conductivity and electromagnetic interference shielding of multiwalled carbon nanotube composites containing Fe catalyst. Appl Phys Lett. 2004;84(4): 589-591.

15. Yuen SM, Ma CCM, Chuang CY, et al. Effect of processing method on the shielding effectiveness of electromagnetic interference of MWCNT/PMMA composites. Compos Sci Technol. 2008;68(3-4): 963-968.

16. Huang YL, Yuen SM, Ma CCM, et al. Morphological, electrical, electromagnetic interference (EMI) shielding, and tribological properties of functionalized multi-walled carbon nanotube/poly methyl methacrylate (PMMA) composites. Compos Sci Technol. 2009;69(11-12): 1991-1996.

17. Capadona JR, Van Den Berg O, Capadona LA, et al. A versatile approach for the processing of polymer nanocomposites with selfassembled nanofibre templates. Nature Nanotechnol. 2007;2(12): 765-769.

18. Miaudet P, Derre A, Maugey M, et al. Shape and temperature memory of nanocomposites with broadened glass transition. Science. 2007;318(5854) 1294-1296.

19. Ci L, Suhr J, Pushparaj V, Zhang X, Ajayan PM. Continuous carbon nanotube reinforced composites. Nano Lett. 2008;8(9):2762-2766.

20. Cheng QF, Bao JW, Park J, Liang ZY, Zhang C, Wang B. High mechanical performance composite conductor: multi-walled carbon na006Eotube sheet/Bismaleimide nanocomposites. Adv Funct Mater. 2009;19(20):3219-3225.
21. Ma WJ, Liu LQ, Zhang Z, et al. High-strength composite fibers: realizing true potential of carbon nanotubes in polymer matrix through continuous reticulate architecture and molecular level couplings. Nano Lett. 2009;9(8):2855-2861.

22. Shim BS, Zhu J, Jan E, et al. Multiparameter structural optimization of single-walled carbon nanotube composites: toward record strength, stiffness, and toughness. ACS Nano. 2009;3(7):1711-1722.

23. Zeng Y, Ci LJ, Carey BJ, Vajtai R, Ajayan PM. Design and reinforcement: vertically aligned carbon nanotube-based sandwich composites ACS Nano. 2010;4(11):6798-6804.

24. Geng HZ, Rosen R, Zheng B, et al. Fabrication and properties of composites of poly(ethylene oxide) and functionalized carbon nanotubes. Adv Mater. 2002;14(19):1387-1390.

25. Sennett M, Welsh E, Wright JB, Li WZ, Wen JG, Ren ZF. Dispersion and alignment of carbon nanotubes in polycarbonate. Appl Phys a-Mater. 2003;76(1):111-113.

26. Shofner ML, Khabashesku VN, Barrera EV. Processing and mechanical properties of fluorinated single-wall carbon nanotube-polyethylene composites. Chem Mater. 2006;18(4):906-913.

27. Ebbesen TW, Lezec HJ, Hiura H, Bennett JW, Ghaemi HF, Thio T. Electrical conductivity of individual carbon nanotubes. Nature. 1996; 382(6586):54-56

28. Treacy MMJ, Ebbesen TW, Gibson JM. Exceptionally high Young's modulus observed for individual carbon nanotubes. Nature. 1996;381(6584):678-680.

29. Benoit JM, Gilmour CC, Mason RP. The influence of sulfide on solidphase mercury bioavailability for methylation by pure cultures of Desulfobulbus propionicus (1pr3). Environ Sci Technol. 2001;35(1): $127-132$.

30. Dai JF, Wang Q, Li WX, Wei ZQ, Xu GJ. Properties of well aligned SWNT modified poly (methyl methacrylate) nanocomposites. Mater Lett. 2007;61(1):27-29.

31. Skakalova V, Kaiser AB, Dettlaff-Weglikowska U, Hrncarikova K, Roth S. Effect of chemical treatment on electrical conductivity, infrared absorption, and Raman spectra of single-walled carbon nanotubes. J Phys Chem B. 2005;109(15):7174-7181.

32. Chauvet O, Benoit JM, Corraze B. Electrical, magneto-transport and localization of charge carriers in nanocomposites based on carbon nanotubes. Carbon. 2004;42(5-6):949-952.

33. Chen H, Muthuraman H, Stokes P, et al. Dispersion of carbon nanotubes and polymer nanocomposite fabrication using trifluoroacetic acid as a co-solvent. Nanotechnol. 2007;18(41).

34. Liu CX, Choi JW. Improved dispersion of carbon nanotubes in polymers at high concentrations. Nanomaterials. 2012;2(4):329-347.

35. Kalakonda P, Cabrera Y, Judith R, Georgiev GY, Cebe P, Iannacchione GS. Studies of electrical and thermal conductivities of sheared multi-walled carbon nanotube with isotactic polypropylene polymer composites. Nanomaterials and Nanotechnology. 2013;(5):1-7.

36. Kohlmeyer RR, Javadi A, Pradhan B, et al. Electrical and dielectric properties of hydroxylated carbon nanotube-elastomer composites. J Phys Chem C. 2009;113(41):17626-17629.

37. Rajendran S, Uma T. Effect of ceramic oxide on PMMA based polymer electrolyte systems. Mater Lett. 2000;45(3-4):191-196.

38. Rajendran S, Uma T. Lithium ion conduction in PVC-LiBF4 electrolytes gelled with PMMA. J Power Sources. 2000;88(2):282-285.

39. Wei Y, Kong LT, Yang R, Wang L, Liu JH, Huang XJ. Electrochemical impedance determination of polychlorinated biphenyl using a pyrenecyclodextrin-decorated single-walled carbon nanotube hybrid. Chem Commun (Camb). 2011;47(18):5340-5342.

40. Vukovic GD, Marinkovic AD, Skapin SD, et al. Removal of lead from water by amino modified multi-walled carbon nanotubes. Chem Eng J. 2011;173(3):855-865.

41. Kalakonda P, Iannacchione GS, Daly M, et al. Calorimetric study of nanocomposites of multiwalled carbon nanotubes and isotactic polypropylene polymer. J Appl Polym Sci. 2013;130:587-594. 
Nanotechnology, Science and Applications is an international, peer-reviewed, open access journal that focuses on the science of nanotechnology in a wide range of industrial and academic applications. It is characterized by the rapid reporting across all sectors, including engineering, optics, bio-medicine, cosmetics, textiles, resource sustainability and science. Applied research into nano-materials, particles, nano-structures and fabrication, diagnostics and analytics, drug delivery and toxicology constitute the primary direction of the journal. The manuscript management system is completely online and includes a very quick and fair peer-review system, which is all easy to use. Visit http://www.dovepress.com testimonials.php to read real quotes from published authors. 